\title{
LOS EFECTOS DE LA CONTAMINACION CON TOLUENO EN LAS COMUNIDADES EPILITICAS BACTERIANAS \\ EN UN ARROYO
}

Indhira I. De Jesús, MS*

\section{Resumen:}

Los efectos de la contaminación con tolueno en las comunidades epilíticas bacterianas en un arroyo fueron estudiados comparando muestras provenientes de la parte contaminada del arroyo con muestras de la parte limpia. Dicha comparación fue basada en la habilidad relativa de cada comunidad para degradar tolueno, en la abundancia relativa de organismos capaces de degradar tolueno, y en la respectiva proporción de organismos degradadores de tolueno dentro de la comunidad heterotrófica. Se encontró que muestras tomadas en la parte contaminada del arroyo eran capaces de degradar tolueno aproximadamente diez veces más rápido que aquellas tomadas de la parte no contaminada. Bacterias con la capacidad de degradar tolueno forman de un 4 a un $7 \%$ de la comunidad heterotrófica en la parte contaminada, mientras que estas bacterias forman sólo un 0.12 a $0.14 \%$ de la población heterotrofica en la parte limpia. Sin embargo, números totales de bacterias y números totales de heterotrofos, con respecto al peso de biomasa, no ha sido significativamente afectado por la presencia del tolueno. Nuestros resultados indican que la comunidad epilítica bacteriana se ha adaptado a la presencia del tolueno en el arroyo.

\section{Palabras Claves:}

Tolueno, contaminación, comunidades epilíticas, comunidades heterotroficas, biodegradación.

* Profesora del Area de Ingeniería Civil del INTEC. 


\section{INTRODUCCION:}

La contaminación del ambiente natural con hidrocarburos, tanto de origen natural como sintético, ha sido motivo de preocupación creciente en las dos últimas décadas. Puesto que se ha encontrado que los microorganismos con la habilidad de degradarhidrocarburos son ubícuos en la naturaleza (Atlas, 1981), una considerable cantidad de investigación se ha destinado al estudio del uso potencial de la microflora indígena a una zona, como herramienta para la limpieza de sitios contaminados (Atlas, 1984; Leahy \& Colwell, 1990). Como parte de este esfuerzo investigador, varios estudios se han concentrado en determinar si una exposición previa a hidrocarburos hace que una comunidad bacteriana esté mejor adaptada para manejar contaminaciones subsecuentes, ic. si su potencial para biodegradar los hidrocarburos aumentaría (Leahy \& Colwell, 1990).

Diversos investigadores han encontrado que las comunidades bacterianas tienden a adaptarse a su ambiente contaminado (Spain et al., 1980; Spain et al., 1983). Se dice que esta adaptación ocurre a través de tres mecanismos principales: induccion/represión de enzimas; mutaciones que resultan en nuevas capacidades metabólicas; y/o, crecimiento preferencial de aquellos organismos capaces de degradar la o las substancias de interés. Por lo tantos se puede inferir, que la adaptación de una comunidad probablemente causará cambios en su estructura (Bossert \& Bartha, 1984). Estos cambios suelen ser difíciles de predecir, principalmente debido a los distintos efectos que un contaminante pueda tener en los distintos miembros del conjunto bacteriano (Pfaender \& Buckley, 1984).

En este artículo se estudiarán los efectos de la contaminación con tolueno sobre la comunidad bacteriana epilítica en un arroyo de agua dulce. Se centrará en los cambios en la comunidad de bacterias capaces de degradar el tolueno al ser influenciada por una pluma de tolueno y otros contaminantes en el arroyo. En este estudio, el énfasis ha sido puesto en la abundancia relativa de bacterias con la capacidad de degradar tolueno y en la habilidad relativa de las comunidades para degradar dicho compuesto químico. Se han hecho comparaciones sobre 
la base del conteo total de bacterias y el conteo de bacteria heterotrofica cultivable, esto nos ha permitido llegar a conclusiones preliminares sobre los efectos de la presencia del contaminante en el conjunto bacteriano.

El lugar objeto de nuestro estudio fue la "Zanja Oriental de Drenaje (ZOD)" (East Drainage Ditch). Este es un arroyo de agua dulce ubicado en la parte nordeste del estado de Massachusetts, y es parte de la cuenca del río Aberjona. Este arroyo está contaminado con tolueno, entre otros compuestos volátiles, el cual se sospecha que provenga de una pluma de agua subterránea. Aguas abajo del sitio de estudio, la ZOD corre a través de un parque industrial abandonado, llamado Industriplex, el cual fue designado como un sitio del "superfund" en 1982 (Durant, 1991). Concentraciones de tolueno de hasta $350 \mathrm{ppb}$ han sido medidas en las aguas del arroyo (Cohen et al., 1994). En un estudio relacionado, llevado a cabo por Kim et al.(1994), se encontró que la biodegradación era el más importante sumidero de tolueno en este lugar. También se determinó que la comunidad bacteriana mayormente responsable por esta degradación era aquella adherida a las rocas y a los sedimentos que forran el fondo del arroyo. Nosotros hemos elegido estudiar las comunidades epilíticas, principalmente porque estos organismos están expuestos más directamente a las sustancias disueltas en el agua y se sabe que poseen un potencial biodegradante significativo.

Mediciones de la concentración de tolueno en el agua del arroyo muestran que existe muy poco tolueno $(0-6 \mathrm{ppb}) 50 \mathrm{~m}$ aguas arriba de la fuente del contaminante, y que no existen rastros de tolueno $100 \mathrm{~m}$ aguas arriba de la fuente. Esta situación nos dio la oportunidad de observar cómo la presencia del tolueno ha influenciado a la comunidad bacteriana. Se ha realizado una comparación entre la habilidad relativa, tanto de las comunidades expuestas al tolueno como de aquellas que no están expuestas a él, para degradar el contaminante; así como de la abundancia relativa de organismos con la capacidad para degradar el tolueno en estas comunidades. 


\section{MÉTODOS Y MATERIALES:}

\section{Condiciones y ubicación de los muestreos}

Todas las muestras para este estudios fueron recolectadas en la ZDO, un arroyo de agua dulce que forma parte de la cuenca del río Aberjona, en el noreste de Massachusetts. Se comenzó a tomar las muestras en Junio y se continuó hasta Septiembre del 1993. Temperaturas promedio en el área durante esta época del año varían entre 20 y $25^{\circ} \mathrm{C}$. Se han medido caudales entre 25 y $40 \mathrm{~m} 3 / \mathrm{hr}$ para los meses del verano (Kim et al, 1994).

La cuenca del río Aberjona ha sido el escenario de una amplia actividad industrial desde principios de siglo. Las industrias localizadas en la cuenca incluyen curado de pieles y manufactura de productos químicos. Partes del ZDO están contaminadas con metales, tales como arsénico y cromo, y con una gran variedad de compuestos orgánicos, tales como el tolueno, el cual parecía estar siendo introducido en el arroyo por una pluma de agua subterránea contaminada (Durant, 1991). La introducción en el arroyo del agua contaminada parece estar ocurriendo debajo de una alcantarilla que tiene aproximadamente $80 \mathrm{~m}$ de largo. Esta alcantarilla está localizada a unos $1,600 \mathrm{~m}$ aguas arriba de la confluencia del la ZDO con Halls Brook. Debido a esto, la localización de los puntos de muestreo es relativa a su distancia aguas arriba de la entrada de la alcantarilla o aguas abajo de la salida del mismo.

Determinación de los niveles de Tolueno en el agua del arroyo.

Para determinar las concentraciones de tolueno en las aguas de la ZDO, muestras de agua fueron recolectadas a 100,50 y $1 \mathrm{~m}$ aguas arriba y a 5,50 y $100 \mathrm{~m}$ aguas abajo de la alcantarilla. Las muestras fueron recogidas en duplicado, en volúmenes de $25 \mathrm{ml}$, utilizándose viales EPA de $40 \mathrm{ml}$, provistos de tapas de rosca huecas con septa cubierta de Teflon. Cloruro de mercurio fue añadido a las muestras para una concentración final de $15 \mathrm{mg} / \mathrm{l}$. Soluciones acuosas de tolueno fueron preparadas como estándares en concentraciones de $0,0.22,0.54,1.08$, $5.43 \mu \mathrm{M}(0,20,50,100$, y $500 \mathrm{ppb})$. La cantidad necesaria de tolueno 
fue añadida a cada estándar en un $\mathrm{ml}$ de metanol. Un $\mathrm{ml}$ de metanol fue también añadido a cada muestra para homogeneizar las condiciones. Tanto las muestras como los estándares fueron sacudidas por dos horas para alcanzar equilibrio. Una muestra de un $\mathrm{ml}$ fue tomada del espacio de aire tanto de las muestras como de los estándares, y el tolueno presente en la muestra fue cuantificado utilizando un Cromatógrafo de Gas, Carlo Erba HRGC 5300 Mega Series (Fison Instruments, Valencia, California), equipado con una columna capilar Restek RTX-5 y un detector de flama ionizadora. La temperatura del homo se mantuvo constante a $40^{\circ} \mathrm{C}$ por $2 \mathrm{~min}$., y luego se aumentó gradualmente hasta $120^{\circ} \mathrm{C}$, con una tasa de incremento de $10^{\circ} \mathrm{C} / \mathrm{min}$.

\section{Determinación de la tasa de biodegradación}

Se dispusieron reactores de bache para determinar las tasas de biodegradación. La pérdida de tolueno de cada reactor se midió utilizando cromatografia de gas, con el mismo instrumento descrito anteriormente. Nuestras muestras consistían en rocas recogidas del fondo de la ZDO. Los lugares de muestreo están localizados a 100 y 50 $\mathrm{m}$ aguas arriba, y 5 y $50 \mathrm{~m}$ aguas abajo de la alcantarilla. Las muestras fueron conservadas a $4^{\circ} \mathrm{C}$ y usadas antes de las 24 horas después de la recolección. Se tuvo cuidado al manipular las muestras para evitar daño excesivo a la biomasa adherida a las rocas.

Estos experimentos fueron realizados usando jarras de fondo redondo de $500 \mathrm{ml}$ de capacidad, a las que se le adaptaron tapones de cristal. Todos los ensayos fueron realizados en duplicado. En cada jarra se colocaron $250 \mathrm{ml}$ del agua del arroyo. Las jarras fueron sacudidas por 1 hora para alcanzar equilibrio, y luego se determino la cantidad de tolueno en el agua. Luego se añadió tolueno en cada jarra para alcanzar una concentración final entre 2.17 y $2.71 \mu \mathrm{M}(200$ a $250 \mathrm{ppb})$. Se permitió que el agua se equilibrara de nuevo y luego se introdujo en cada jarra $80 \mathrm{~g}(+-2.8 \mathrm{~g})$ de rocas. A continuación se procedió a determinar la concentración inicial de tolueno. Las jarras fueron sacudidas por 8.5 horas a $22^{\circ} \mathrm{C}$. Cada 1.5 horas una muestra de $1 \mathrm{ml}$ del espacio de aire era tomada de cada jarra en una jeringa hermética e inyectada en el cromatógrafo (GC) para ser analizada. También se corrieron controles 
envenenados con cloruro de mercurio para tener una medida de las perdidas abióticas de tolueno.

Los datos obtenidos en el GC fueron graficados contra tiempo, y la ecuación que mejor describe la relación se obtuvo utilizando el método de los mínimos cuadrados. La pendiente de esta línea es la tasa de degradación. Los datos fueron homogeneizados utilizando el peso de piedras y no su área superficial debido a las características del fondo de la ZDO. Los sedimentos en la zanja se vuelven rápidamente anaerobios al aumentar la profundidad, de tal forma que solamente una porción de cada roca podía estar soportando una comunidad aerobica en un momento dado. Todas las rocas utilizadas eran muy similares en tamaño $y$ forma.

\section{Cuantificación de microorganismos epilíticos. \\ Conteo directo total}

Muestras de rocas fueron tomadas de los mismos puntos descritos más arriba. La biomasa en cada roca fue raspada utilizando una pequeña espátula estéril. $0.2 \mathrm{~g}$ de biomasa de cada lugar fueron resuspendidos en una solución de sales mínima (MS, esta solución contiene por cada litro de agua destilada: $10.55 \mathrm{~g} \mathrm{Na}_{2} \mathrm{HPO}_{4} ; 3.5 \mathrm{~g} \mathrm{KH}_{2} \mathrm{PO}_{4} ; 1.5 \mathrm{~g} \mathrm{NH}_{4} \mathrm{Cl} ; 0.5 \mathrm{~g}$ $\mathrm{CaCl}_{2}$; y $5.0 \mathrm{~g} \mathrm{NaNO}_{3} ; 1 \mathrm{ml}$ de una solución de rastros de elementos fue añadida después de esterilizar), y sacudida por 5 minutos para asegurar adecuada separacion (Hobbie et al, 1977). Las muestras fueron luego fijadas utilizando una solución de glutaraldehido- cacodilato (concentración final: $2 \%$ glutaraldehido, y $0.1 \mathrm{M}$ cacodilato). Sucesivas diluciones en glutaraldehido fueron realizadas según fuese necesario.

Submuestras de $1 \mathrm{ml}$ fueron teñidas con $10 \mu \mathrm{l}$ de una solución DAPI(4',6-diamidino-2-phenylindole) de $10 \mathrm{mg} / \mathrm{ml}$ por $10 \mathrm{~min}$. Luego se filtraron a través de filtro negro de membrana de policarbonato de $0.2 \mu \mathrm{m}$ de apertura de poros (Millipore Co.). Las células bacterianas retenidas en el filtro fueron luego contadas bajo un microscopio epifluorescente. Por lo menos 20 celdas y 300 células fueron contadas. Todas las muestras fueron contadas en duplicados. Células que parecían 
estar adheridas a una partícula fueron contadas dos veces, asumiendo que habría el mismo número en el otro lado.

\section{Conteos totales de bacterias heterótrofas}

Muestras de rocas fueron tomadas de los mismos lugares y bajo las mismas condiciones que se describieron arriba. La biomasa fue raspada de la superficie de las rocas. 0.2 gramos de biomasa de cada punto de muestreo fueron resuspendidos en solución MS, y sacudidospor 5 minutos en un batidor de acción de muñeca. La suspensión de células resultante fue sucesivamente diluida para obtener diluciones desde $10^{-2}$ hasta $10^{-7} .0 .10 \mathrm{ml}$ de cada una de estas diluciones fueron regados sobre platos petri utilizando un rodillo de cristal. Cada plato contenía 35 $\mathrm{ml}$ de agar Peptona-Triptosa-Extracto de levadura-Glucosa (PTYG, por sus siglas en inglés) al $1 \%$. Los platos fueron incubados en la obscuridad, a $20^{\circ} \mathrm{C}$ por tres semanas. Las colonias fueron contadas cada tres días, hasta que no se observaba más crecimiento.

\section{Conteo de platos de bacterias utilizadoras de tolueno}

Muestras de bacterias epilíticas fueron recogidas como se describe arriba. Se prepararon las diluciones y se inocularon platos petri conteniendo $35 \mathrm{ml}$ de agar MS. Luego de inocularlos los platos se colocaron en contenedores de cristal herméticamente cerrados. Dentro de estos contenedores también se coloc 6 un recipiente con agua saturada de tolueno. La cantidad de agua saturada de tolueno se determinó de tal forma que la concentración final en el agar (después de equilibrio) fuera de $0.11 \mathrm{mM}(10 \mathrm{ppm})$.

Luego se incubaron en la oscuridad por tres semanas a $20^{\circ} \mathrm{C}$, los contenedores eran abiertos y el agua saturada de tolueno repuesta cada tres días. A este mismo intervalo eran contadas las colonias. Platos de control, en sistemas sin tolueno, fueron también incubados de la misma forma. 


\section{Estimación de el número mas probable de bacterias mineralizadoras de tolueno}

Para la determinación del número más probable (MPN, por sus siglas en inglés) de bacterias degradadoras de tolueno se desarrollo un protocolo para cuantificar aquellas bacterias capaces de convertir tolueno marcado con ${ }^{14} \mathrm{C}$ (etiqueta en el anillo, actividad específica $9.7 \mathrm{mCi}$ / mmol; Sigma Chemical Co.) a ${ }^{14} \mathrm{CO}_{2}$. La técnica utilizada fue una adaptación de la descrita por Lehmicke et al (1979). Muestras de rocas fueron recogidas y preparadas como se ha descrito. Un ml de medio MS fue colocado en un vial de cristal de $1 / 2$ dram, y fue inoculado con 100 $\mu l$ de la dilución correspondiente. Se prepararon seis diluciones $\left(10^{-2}-\right.$ $10^{-7}$ ), y se inocularon 5 viales por cada dilución. Los viales inoculados se colocaron en una botella de serum de $40 \mathrm{ml}$ invertida, la cual fue luego tapada con un tapón cubierto de Teflon, y sellada. Manteniendo la botella invertida, un $\mathrm{ml}$ de $0.5 \mathrm{M} \mathrm{NaOH}$, destinado a atrapar el ${ }^{14} \mathrm{CO}_{2}$ formado, fue inyectado a cada botella. $\mathrm{Al} \mathrm{NaOH}$ se añadio tolueno suficiente para obtener una concentración final en la botella de $1.08 \mu \mathrm{M}$ (100 ppb). Aproximadamente $0.01 \mu \mathrm{Ci}$ (ca. 10,000 cuentas por minuto), en tolueno radioactivo, fueron colocados en cada botella. Este protocolo nos permitió trabajar con un substrato volátil sin necesidad de un solvente, y sin que ocurrieran pérdidas por absorción a las paredes del vial.

Después de un mes de incubación en la oscuridad a $20^{\circ} \mathrm{C}$, las botellas fueron abiertas y los viales internos fueron sacados. Las botellas se dejaron abiertas durante la noche bajo un ventilador para permitir que todo el tolueno no mineralizado escapara. Al otro día $10 \mathrm{ml}$ de cocktail para escintilación fueron añadidos a cada botella, mezclado con el hidróxido de sodio y luego transferidos a un vial para escintilación. La cantidad de ${ }^{14} \mathrm{CO}_{2}$ atrapada en el $\mathrm{NaOH}$ fue determinada por conteo de escintilación liquido. Cada botella se conto dos veces, por diez minutos cada vez.

También se corrieron controles positivos, los cuales fueron inoculados con un cultivo puro de bacterias degradadoras de tolueno. También se prepararon controles negativos con viales no inoculados. Aquellos 
viales con un conteo de al menos el doble de los controles negativos, fueron señalados como positivos. Se determinó una eficiencia de atrape del ${ }^{14} \mathrm{CO}_{2}$ de un $100 \%$, utilizando $\mathrm{NaH}^{14} \mathrm{CO}_{3}$. Los valores del MPN fueron obtenidos de las tablas en Greenberg et al (eds.), 1993.

\section{RESULTADOS:}

\section{Concentración de tolueno en la ZDO.}

Las concentraciones promedios de tolueno encontradas en el agua de la ZDO en las dos fechas de muestreo han sido graficadas a continuación:

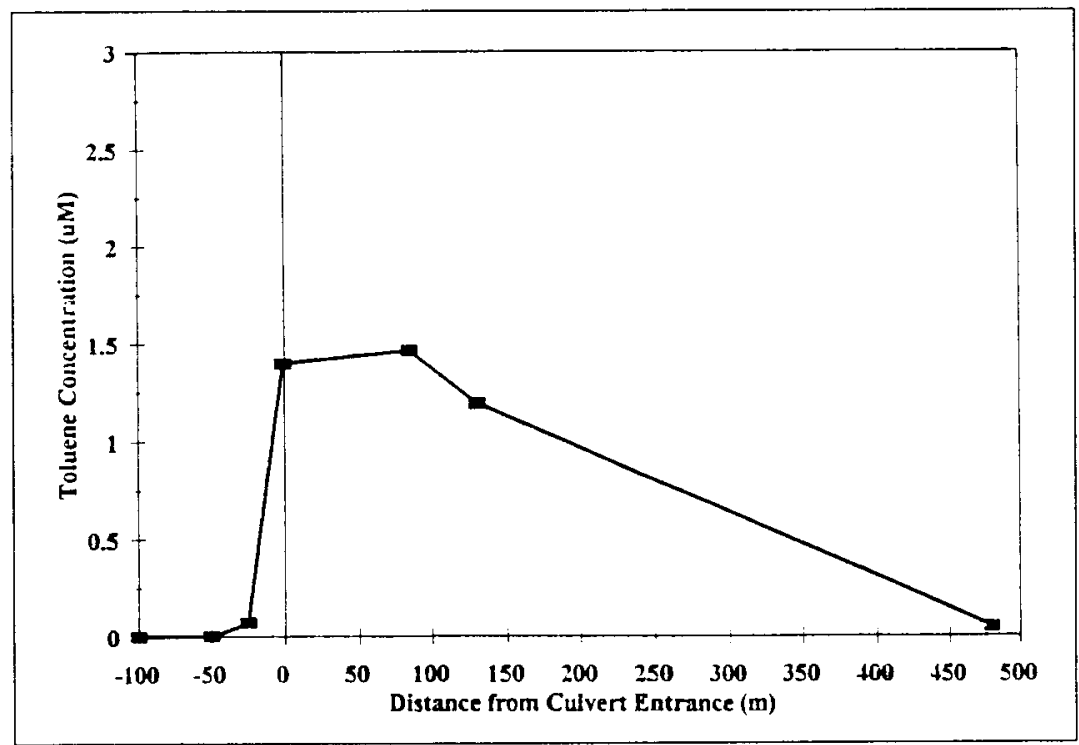

Figura 1: Gráfica de la concentración de tolueno en el agua de la ZDO.

\section{Determinación de la tasa de biodegradación}

Con esta parte del experimento se buscaba determinar si existe una correlación entre la concentración de tolueno en el agua y la rapidez con que es degradado por los microorganismos. Los resultados individuales para una de las fechas de muestreo han sido graficados en la Figura 2. 
En esta gráfica, cada punto en la serie de tiempo para un lugar determinado representa la concentración promedio de los duplicados. La desviación estándar nunca es mayor del 5\% del promedio correspondiente.

Estos resultados indican que aquellas muestras recogidas a $100 \mathrm{~m}$ aguas arriba de la alcantarilla, donde no se encontró tolueno en el agua, tienen tasa de degradación que no difieren significativamente de aquellas de los controles negativos (prueba t, nivel de seguridad de 90\%). Esto sugiere que la perdida de tolueno en esos reactores se debió, mayormente, a mecanismos abióticos. También se observa que para aquellas muestras tomadas a $50 \mathrm{~m}$ de la alcantarilla, donde la concentración de tolueno varía de 0 a $6 \mathrm{ppb}$, la tasa promedio de degradación es casi tres veces mayor que la del punto anterior, pero casi un orden de magnitud menor que la de las muestras tomadas en la parte contaminada. Ambos puntos de muestreo localizados aguas abajo de la fuente de tolueno, 5 y $50 \mathrm{~m}$ aguas abajo, tienen tasas similares.

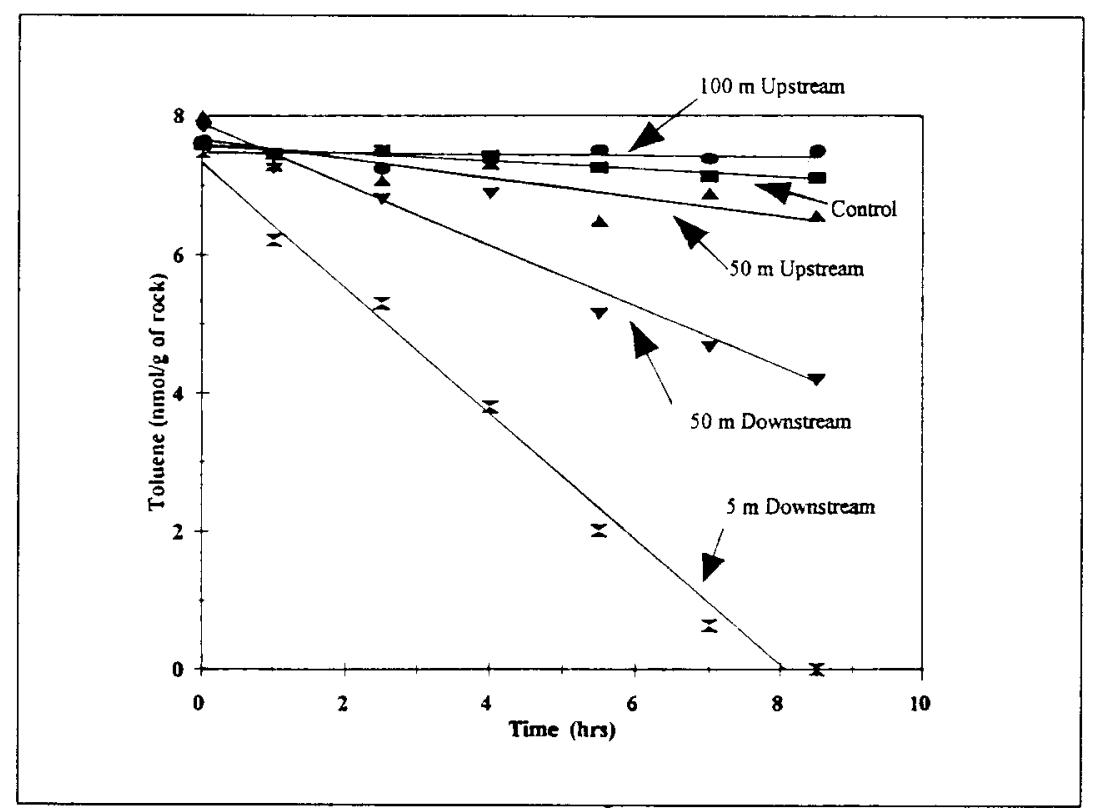

Figura 2: Tasas de biodegradación de las muestras provenientes de cada uno de los cuatro puntos de muestreo. 
Cuantificación de micoorganismos epilíticos.

Conteos directos totales

Los resultados de la determinación de los números totales de bacteria por conteo directo han sido graficados en la Figura 3, donde se les relaciona con la concentración de tolueno. Se puede observar que, aparentemente, los números totales de bacterias no han sido influenciados significativamente por la presencia del contaminante.

\section{Conteo de bacterias heterótrofas totales}

Estos resultados también han sido graficados en la Figura 3, y al igual que para bacterias totales, el número de heterótrofas en las muestras no parece haber sido influenciada por la cantidad de tolueno.

\section{Conteo de bacterias degradadoras de tolueno}

Los números de degradadores de tolueno en las muestras, según fueron determinados por este método, sigue la tendencia de la concentración (Fig. 3)

\section{Número más probable de degradadores de tolueno}

Los resultados de este experimento indican una fuerte correlación entre el nivel del tolueno en el agua y la cantidad de bacterias con la capacidad para mineralizarlo dentro de las comunidades epilíticas. Ver Figura 3. Con este método pudo determinarse que existen bacterias degradadoras de tolueno aún donde no se encontró este contaminante, aunque en este lugar ellas forman una mínima parte del total de organismos. 


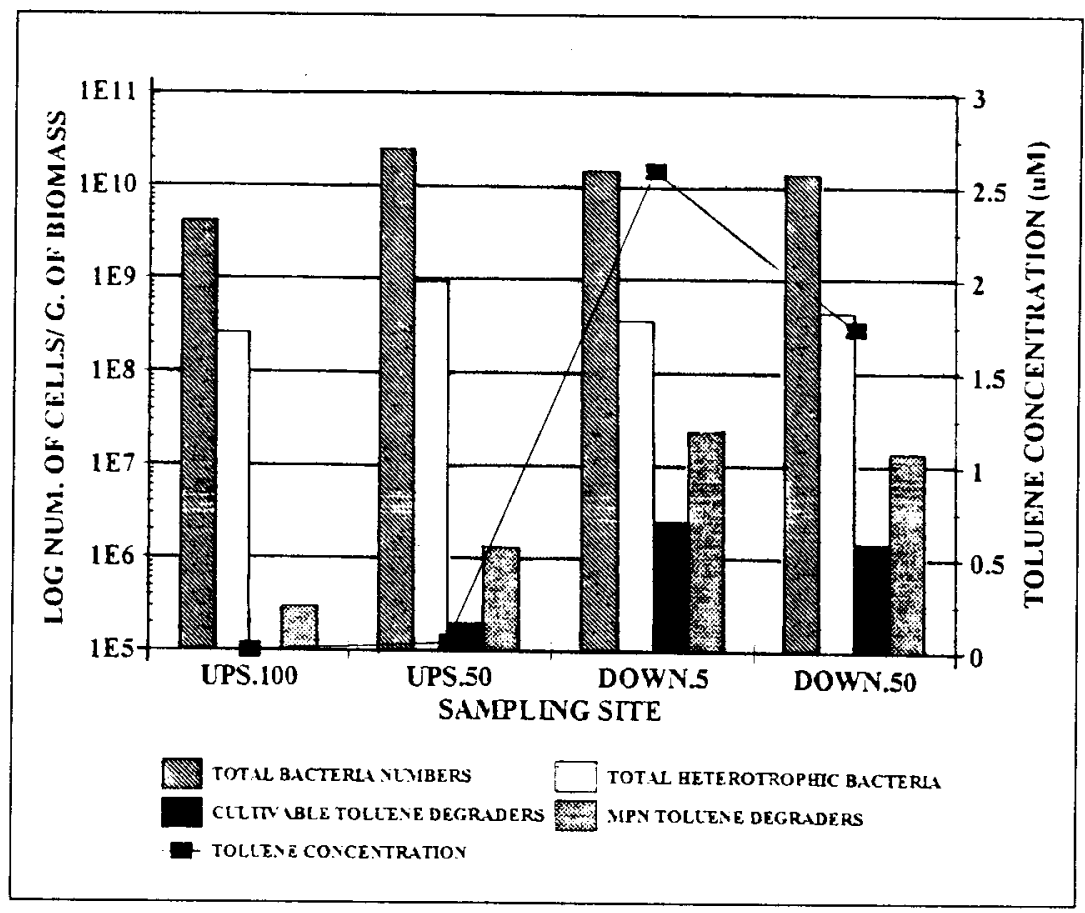

Figura 3: Comparación de los números totales de bacterias, los números totales de bacterias heterotróficas, MPN de bacterias con la capacidad de degradar tolueno y conteo de platos de las mismas en cada punto de muestreo dentro del arroyo, y su relación con la concentración de tolueno en el agua de dicho punto.

\section{DISCUSIÓN:}

Utilizando la información recolectada en los experimentos descritos anteriormente para determinar el impacto de la contaminación con tolueno en las comunidades bacterianas epilíticas en la ZDO, se puede llegar a una conclusión principal: mayores concentraciones de tolueno correlacionan con un incremento en la habilidad de la comunidad para degradar el contaminante. Por otro lado, los niveles de tolueno en el agua no parecen tener influencia en los números totales de bacterias o en los números totales de bacterias heterótrofas, en relación con el peso de la biomasa. 
La forma en que la presencia del contaminante afecta los números totales de bacterias y la población heterotrofica depende, mayormente, de las características del ambiente donde la comunidad se desarrolla, y en las características propias de la comunidad (Pfaender y Buckley, 1984). Estudios realizados por Spain et al (1984), y por Pignatello et al (1986) han reportado números de heterotrofos que no han sido afectados por la presencia de un contaminante xenobiótico (p-nitrofenol y pentaclorofenol, respectivamente). Pignatello et al(1986) interpreta este resultado como una indicacion de que el contaminante no resulta tóxico para la mayoría de los miembros de la comunidad bacteriana, en las concentraciones presentes en el estudio. En un artículo relacionado, se reporto que no se observaron aumentos en los números totales de bacterias debido a la adaptación de la comunidad al pentaclorofenol (Pignatello et al., 1983).

Incrementos en las tasas de biodegradación en comunidades bacterianas que han tenido la oportunidad de adaptarse a un contaminante han sido reportados en varios estudios diferentes (Atlas, 1984; Bossert y Bartha, 1984; Leahy y Colwell, 1990; Pignatello et al., 1983; Spain et al., 1980, 1984). En el caso de las muestras tomadas de la parte contaminada de la ZDO, las comunidades epilíticas han estado expuestas al tolueno por muchos años, por lo tanto es de esperarse que estén bien adaptadas a su presencia (Kim et al., 1994). Nuestros resultados indican que las muestras provenientes de la parte contaminada son capaces de degradar el tolueno aproximadamente diez veces mas rápido que aquellas provenientes de la parte limpia. En estudios de campo, Spain et al., (1984) reportaron un incremento de dos ordenes de magnitud en la tasa de biodegradación de p-nitrofenol en comunidades adaptadas en comparación con las que no habían sido expuestas al contaminante. Resultados similares fueron obtenidos en estudios de laboratorio de la biodegradación del p-cresol (Van Veld y Spain, 1983); también, un incremento de diez veces fue observado en la tasa correspondiente para $\mathrm{p}$-nitrofenol y para methyl paration.

Nuestros estudios de biodegradación indican que la reacción es de cero orden con respecto a la concentración. Esto significa que el proceso no está limitado por la cantidad de substrato presente en el reactor. 
Cohen et al.(1994) reportó tasas de biodegradación para muestras de la ZDO que eran independientes de la concentración para concentraciones por encima de los $250 \mathrm{ppb}$. En procesos biológicos, las reacciones sólo parecen ser de primer orden con respecto a la concentración del substrato cuando el número y la actividad de los microorganismos responsables de la degradación se mantienen constantes (Van Veld y Spain, 1983). Por lo tanto, lo que nosotros estamos observando puede ser el resultado del crecimiento que está ocurriendo en los reactores.

Números elevados de bacteria degradadora de tolueno en las muestras provenientes de la parte contaminada del arroyo en comparación con los resultados obtenidos de las muestras de la parte limpia, también es un indicador de que esta es una comunidad bien adaptada (Pignatello et al., 1983, 1985, 1986; Spain et al., 1980, 1983, 1984). Spain et al. reportaron que, en promedio, el número de organismos capaces de degradar el contaminante de interés aumenta en tres ordenes de magnitud después de la adaptación. Pignatello et al. (1986) reportaron que la población de organismos capaces de degradar pentaclorofenol aumentó en dos ordenes de magnitud después de ocurrida la adaptación, con respecto de una población base encontrada antes de añadir el contaminante. Estos últimos resultados fueron obtenidos utilizando un procedimiento de MPN similar al utilizado por nosotros. Nuestros resultados en la determinación del número más probable indican que ha habido un incremento de dos ordenes de magnitud entre la parte limpia y la parte contaminada del arroyo. Laexistencia de una población de degradadores de tolueno mayor en el punto de muestreo ubicado a $50 \mathrm{~m}$ aguas arriba de la alcantarilla con respecto al punto $100 \mathrm{~m}$ aguas arriba probablemente se debe a la presencia esporádica de pequeñas cantidades de tolueno en este lugar.

El hecho de que se haya cuantificado bacterias con la capacidad de mineralizar tolueno en el punto de muestreo ubicado $100 \mathrm{~m}$ aguas arriba de la fuente del contaminante, sugiere que el elevado número de bacterias con dicha capacidad que ahora se encuentran en los puntos más contaminados creció a partir de una población de organismos con la capacidad innata de degradar tolueno u otros hidrocarburos similares, ie. ocurrio un proceso de enriquecimiento selectivo (Spain et al., 1983). 
Pero nuestros experimentos no pueden ser utilizados para describir categóricamente cuál fue el mecanismo de adaptación de estas comunidades.

En resumen, nuestros resultados sugieren que la comunidad epilítica de bacterias en la parte contaminada con tolueno de la ZDO se han adaptado a la presencia de éste, desarrollándose una gran población de bacterias con la capacidad de degradarlo. Esta población constituye una parte considerablemente mayor de la población total heterotrofica en la parte contaminada que en la limpia. Sin embargo, la exposición al tolueno no ha afectado el número total de bacterias ni el número total de heterotrofas con respecto al peso de biomasa, puesto que estos resultados fueron similares para los cuatro puntos de muestreo.

\section{REFERENCIAS:}

1.- Armstrong, A.Q., R.E. Hodson, H.M. Hwang, and D.L. Lewis. 1991. Environmental factors affecting toluene degradation in ground water at a hazardous waste site. Environmental Toxicology and Chemistry. 10: 147- 158.

2.- Atlas, R.M. 1981. Microbial degradation of petroleum hydrocarbons: an environmental perspective. Microbiology Reviews. 45: 180-209.

3.- Atlas, R.M. (ed.). 1988. Petroleum Microbiology. Macmillan Publishing Co. New York.

4.- Bossert, I., and R. Bartha. 1988. The fate of petroleum in soil ecosystems, pp. 434-476. In R.M. Atlas (ed.), Petroleum Microbiology;Macmillan Publishing Co. New York.

5.- Bowden, W.B. 1977. Comparison of two direct count techniques for enumerating aquatic bacteria. Applied and Environmental Microbiology. 33: 1229-12?.2. 
6.- Cerniglia, C.E. 1988. Microbial transformation of aromatic hydrocarbons, pp. 99-128. In R.M. Atlas (ed.), Petroleum Microbiology. Macmillan Publishing Co. New York.

7.- Cohen, B.A., L.R. Krumholz, H. Kim, and H.F. Hemond. 1994. In-situ biodegradation of toluene in a contaminated stream. Laboratory studies. Submitted to Environmental Science and Technology.

8.- Durant, J.L. 1991. Industrial history, mutagenicity and hydrologic transport of pollutants in the Aberjona watershed. Masters thesis, de-partment of civil and environmental engineering. Massachusetts Institute of Technology.

9.- Gibson, D.T. 1971. The microbial oxidation of aromatic hydrocarbons. CRC Critical Reviews in Microbiology. 1: 199-225.

10.- Greenberg, A.E., L.S. Clescent, and A.D. Eaton (Editors). 1993. Standard Methods for the Examination of Water and Wastewater, 17 th edition.

11.- Hobbie, J.E., R.J. Daley and S. Jasper. 1977. Use of nuclepore filters for counting bacteria by fluorescence microscopy. Applied and Environmental Microbiology. 33: 1225-1228.

12.- Kinkel, L.L., E.V. Nordheim, and J.H. Andrews. 1992. Microbial community analysis in incompletely or destructively sampled systems. Mi-crobial Ecology. 24: 227-242.

13.- Kim, H,H.F. Hemond, and L.R. Krumholz. 1994. In-situ biodegradation of toluene in a contaminated stream. Field studies. Submitted to Environmental Science and Technology.

14.- Lehmicke, L.G., R.T. Williams, and R.L. Crawford. 1979. 14C Most Probable Number method for enumeration of active heterotrophic microor-ganisms in natural waters. Applied and Environmental Microbiology. 38: 644-649. 
15.- Madsen, E.L., J.L. Sinclair, W.C. Ghiorse. 1991. In situ biodegradation: microbial pattems in a contaminated aquifer. Science. 252: 830-832.

16.- Pignatello, J.J., M.M. Martinson, J.G. Steiert, R.E. Carlson, and R.L. Crawford. 1983. Biodegradation and photolysis ofpentachlorophenol in artificial freshwater streams. Applied and Environmental Microbio- logy. 46: 1024-1031

17.- Pignatello, J.J., L.K. Johnson, M.M. Martinson, R.E. Carlson, and R.L. Crawford. 1985. Response of the microflora in outdoor experimental streams to pentachlorophenol. Applied and Environmental Microbiology. 50:127-132.

18.- Pignatello, J.J., L.K. Johnson, M.M. Martinson, R.E. Carlson, and R.L. Crawford. 1986. Response of the microflora in outdoor experimental streams to pentachlorophenol: environmental factors. Canadian Journal of Microbiology. 32:38-46

19.- Pfaender, F.K., and E.N. Buckley. 1988. Effects of petroleum on microbial communities, pp. 507-536. In R.M. Atlas(ed.), Petroleum Microbiology. Macmillan Publishing Co. New York.

20.- Shreve G.S., and T.M. Vogel. 1992. Comparison of substrate utiliza-tion and growth kinetics between immobilized and suspended Pseudomonas cells. Biotechnology and Bioengineering. 41: 370-379

21.- Smith, M.R. 1990. The biodegradation of aromatic hydrocarbon by bacteria. Biodegradation. 1: 199-225.

22.- Somerville, C.C., C.A. Monti, and J.C. Spain. 1985. Modification of the $14 \mathrm{C}$ Most Probable Number method for use with nonpolar and volatile substrates. Applied and Environmental Microbiology. 49: 711-713.

23.- Spain, J.C., P.H. Pritchard, and A.W. Bourquin. 1980. Effects of 
adaptation on biodegradation rates in sediment/water cores from estuarine freshwater environments. Applied and Environmental Microbiology. 40: 726-734.

24.- Spain, J.C., P.A. van Veld. 1983. Adaptation of natural microbial communities to degradation of xenobiotic compounds: effects of concentra-tion, exposure time, inoculum, and chemical structure. Applied and Envi- ronmental Microbiology. 45: 428-435.

25.- Spain, J.C., P.A. van Veld, P.H. Pritchard, C.R. Cripe. 1984. Compa- rison of $\mathrm{p}$-nitrophenol biodegradation in field and laboratory test sys- tems. Applied and Environmental Microbiology. 48: 944-950.

26.- Van Veld, P.A, and J.C. Spain. 1983. Degradation of selected xeno- biotic compounds in three tipes of aquatic test systems. Chemosphere. 12: 1291-1305

27.- Vestal, R., J.J. Cooney, S. Crow, and J. Berger. 1988. The effects of hydrocarbons on aquatic microorganisms, pp. 475-505. In R.M. Atlas (ed.), Petroleum Microbiology. Macmillan Publishing Co. New York.

28.- Yoon, W.B., and R.A. Rosson. 1990. Improved method of enumeration of attached bacteria for study of fluctuation in the abundance of attached and free living bacteria in response to diel variation in seawater turbidity. Applied and Environmental Microbiology. 56: 595-60. 